\title{
Dynamic variations of the peripheral blood immune cell subpopulation in patients with critical H7N9 swine-origin influenza A virus infection: A retrospective small-scale study
}

\author{
CHENG CHEN $^{1 *}$, WEI SUN ${ }^{2 *}$, JUN CHEN $^{2 *}$ and JIAN-AN HUANG ${ }^{1}$ \\ ${ }^{1}$ Respiratory Department and ${ }^{2}$ Intensive Care Unit, The First Affiliated Hospital of Soochow University, \\ Suzhou, Jiangsu 215006, P.R. China
}

Received September 16, 2015; Accepted October 28, 2016

DOI: $10.3892 / \mathrm{etm} .2017 .4144$

\begin{abstract}
H7N9 influenza is a recently emerging infection with a high mortality rate. The aim of the present study was to investigate dynamic fluctuations of peripheral blood immune cell subgroups in patients with critical H7N9 infection. Flow cytometry was used to assess the cells in whole blood samples from 9 cases. With regard to the innate immune system, in the majority of patients, the natural killer (NK) cell counts were similar to those of monocytes, which demonstrated a gradual increase in the progression period and an early increase followed by a reduction during recovery. B cells exhibited a reduction during progression and were further decreased during recovery. The $\mathrm{CD}^{+}{ }^{+} \mathrm{T}$ cells of all patients decreased during progression, and further decreased during recovery. By contrast, $\mathrm{CD}^{+} \mathrm{T}$ cells increased in the majority of patients in the progression stage, and underwent an initial reduction followed by a gradual increase during recovery. However, $\mathrm{CD}^{+}$programmed death (PD) $-1^{+} \mathrm{T}$ cell and $\mathrm{T}$ helper (Th) 1 cell frequencies demonstrated a moderate increase in all patients during the progression stage, and regulatory $\mathrm{T}$ cell (Treg) frequencies tended to be reduced during progression and increased during recovery. Notably, this preliminary data also showed that the frequencies of B cells, Th2 cells and Th17 cells in the progression period were higher than those in the recovery period. The frequencies of monocytes, $\mathrm{CD}^{+} \mathrm{T}$ cell, $\mathrm{CD} 8^{+} \mathrm{T}$ cell, $\mathrm{CD} 4^{+} \mathrm{PD}-1^{+} \mathrm{T}$ cells and $\mathrm{CD} 8^{+} \mathrm{PD}-1^{+} \mathrm{T}$ cells in the
\end{abstract}

Correspondence to: Professor Jian-An Huang, Respiratory Department, The First Affiliated Hospital of Soochow University, 188 Shizi Street, Suzhou, Jiangsu 215006, P.R. China

E-mail: huang_jian_an@163.com

${ }^{*}$ Contributed equally

Abbreviations: NK, natural killer; Treg, regulatory T cell; PD-1, programmed death 1; PE, phycoerythrin; FITC, fluorescein isothiocyanate; PE-Cy5, phycoerythrin-anthocyanidin; ECD, phycoerythrin-Texas red

Key words: H7N9, immune cell, lymphocyte progression period were lower than those during recovery. In conclusion, different levels of peripheral blood immune cell subgroups during the pathogenesis of H7N9 infection may be associated with elimination of the virus and immune damage.

\section{Introduction}

H7N9 influenza is a recently emerging infection and has a high rate of mortality. Typical clinical manifestations include fever, cough, dyspnea and rapid progression of pulmonary infiltration or consolidation $(1,2)$. Cytokines and immune cells regulate the immune response to viral infection, mediate inflammatory responses, and are involved in tissue damage and repair. Following initial infection, the innate immune system of the host, as a first line of defense, reacts earlier than the adaptive immune system to reduce further viral invasion or replication. However, too strong an immune reaction also causes aggravation, and subsequently induces lung injury (3-5). Although successfully eliminating the virus is essential, the response of virus-specific $\mathrm{T}$ cells could also result in tissue damage and autoimmune responses in the host. Therefore, monitoring the variation of cellular immune functions in patients with H7N9 infection has important clinical significance, particularly in critical patients, as it would contribute to the establishment of a predictive immune parameter.

The aim of the present study was to analyze the dynamic fluctuations of T cells, B cells, natural killer (NK) cells and macrophages in patients infected with H7N9 influenza, and to examine the association between persistence of computed tomography (CT) abnormalities and dynamic variations of the peripheral blood immune cell subpopulation.

\section{Materials and methods}

Study subjects. The study subjects comprised 9 patients that were admitted to the First Affiliated Hospital of Soochow University (Suzhou, China) and diagnosed with H7N9 infection from April 1 to April 20, 2013. Diagnosis of H7N9 infection in patients was made by positive throat-swab specimen tests for viral RNA. Among those patients, 8 were male and 1 was female. The ages of the patients ranged from 20 to 75 years, and the median age was 69 years. Two patients succumbed 
during the course of the study; data for 7 and 5 patients were recorded during progression and recovery respectively. In addition, 8 healthy volunteers were enrolled in the study and used as control group. This retrospective, small-scale study was approved by the Ethics and Review Committee of the First Affiliated Hospital of Soochow University.

Clinical manifestations. All patients had been treated with oseltamivir (150 mg twice daily; Roche, Basel, Switzerland) and additionally treated with methylprednisolone (1-2 $\mathrm{mg} / \mathrm{kg} / \mathrm{day})$. Antibiotics given to all patients included moxifloxacin, sulbactam and cefoperazone, levofloxacin, meropenem, piperacillin, imipenem and cilastatin. Some patients also received continuous renal replacement therapy $(n=4)$ and mechanical ventilation therapy $(n=7)$.

Following guidelines from the influenza A H7N9 clinic program published by the National Health and Family Planning Commission of P.R. China (2nd edition, 2013), patients were considered critically ill if they met the following criteria: i) Pneumonia with two or more complications, such as acute respiratory distress syndrome, heart failure, renal failure, septic shock, encephalopathy and secondary infections, and ii) no improvement in at least one of the above mentioned complications after 3 days of active treatment. Recovery was considered by improvement of symptoms, no detectable H7N9 virus in the throat-swab specimens and the initiation of absorption in chest computed tomography images.

Antibodies, sample collection and analysis. Monoclonal antibodies (mAbs) fluorescently labeled with phycoerythrin (PE), fluorescein isothiocyanate (FITC), phycoerythrin-anthocyanidin (PE-Cy5) or phycoerythrin-Texas red (ECD) were used. PE-programmed death 1 (PE-PD-1; cat. no. 557946) $\mathrm{mAb}$ and PE-interleukin (IL)-17A (cat. no. 560486) mAb were purchased from BD Biosciences (San Jose, CA, USA), and the other mAbs were obtained from Beckman Coulter, Inc. (Brea, CA, USA). Results are expressed as the percentages of the T-cell subset in the total lymphocyte population. The samples were analyzed using a flow cytometer (Beckman Coulter Epics XL; Beckman Coulter, Inc.). Data were collected and analyzed using EXPO32 ${ }^{\mathrm{TM}}$ ADC software (Beckman Coulter, Inc.).

Whole blood samples $(2 \mathrm{ml})$ were collected from patients for the detection of $\mathrm{CD} 4^{+} \mathrm{T}$ cells (FITC-CD45 $\mathrm{mAb}$, cat. no. 6603838; PE-Cy5-CD3 mAb, cat. no. 6607010; PE-CD4 mAb, cat. no. IM0449U), CD8 ${ }^{+} \mathrm{T}$ cells (FITC-CD45 mAb; PE-Cy5-CD3 mAb; ECD-CD8 mAb, cat. no. 6604728), NK cells (FITC-CD45 mAb; PE-Cy5-CD3 mAb; PE-CD56 mAb, cat. no. IM2073U), B cells (ECD-CD19 mAb, cat. no. 6604551), regulatory $\mathrm{T}$ cells (Tregs; FITC-CD4 mAb, cat. no. 6602393; PE-Cy5-CD25 mAb, cat. no. IM2646U; PE-CD127 mAb, cat. no. IM1980U), monocytes (PE-CD14 mAb, cat. no. IM0650U; FITC-CD16 mAb, cat. no. 6604894), CD4 ${ }^{+} \mathrm{PD}-1^{+} \mathrm{T}$ cells (PE-Cy5-CD4 mAb, cat. no. IM2636U; PE-PD-1 mAb) and CD8 ${ }^{+} \mathrm{PD}-1^{+} \mathrm{T}$ cells (FITC-CD8 mAb, cat. no. 6602385; PE-PD-1 mAb). Briefly, $100 \mu 1$ sodium citrate anticoagulant was added to the sample in each flow tube and mouse anti-human fluorescence-labeled mAbs were then added $(10 \mu 1)$. After mixing, the samples were incubated for 15 min away from light at room temperature. Red blood cell lysis and cell fixation was conducted using a Coulter Q-Prep specimen processing instrument (Beckman Coulter, Inc.), and $>1 \times 10^{5}$ cells were counted.

For the detection of $\mathrm{T}$ helper $(\mathrm{Th}) 1\left(\mathrm{CD} 3^{+} \mathrm{CD} 8-\mathrm{IFN}-\gamma^{+}\right.$ T cells; ECD-CD3 mAb, cat. no. IM2705U; PE-Cy5-CD8 mAb, cat. no. IM2638U; FITC-IFN- $\gamma$ mAb, cat. no. IM2716U), Th2 (CD3 ${ }^{+}$CD8-IL4 ${ }^{+}$T cells; ECD-CD3 mAb; PE-Cy5-CD8 mAb; PE-IL-4 mAb, cat. no. IM2719U) and Th17 cells $\left(\mathrm{CD}^{+}{ }^{+} \mathrm{CD} 8-\mathrm{IL}^{1} 7^{+} \mathrm{T}\right.$ cells; PE-IL-17A mAb; ECD-CD3 mAb; PE-Cy5-CD8 mAb), $50 \mu 1$ whole blood was treated with hemolysis reagent (BD Pharmingen ${ }^{\mathrm{TM}}$; San Diego, CA, USA) for 4-6 h. Cells were then harvested, stained with ECD-CD3 $\mathrm{mAb}$ and PE-Cy5-CD8 mAb $(10 \mu \mathrm{l})$, permeabilized in IntraPrep Permeabilization Reagent 1 and Reagent 2 (BD Pharmingen $^{\mathrm{TM}}$ ), then stained with FITC-IFN- $\gamma$ mAb, PE-IL-4 $\mathrm{mAb}$ or PE-IL-17A mAb $(10 \mu \mathrm{l})$ according to the manufacturer's recommendations. Flow cytometric acquisition was gated on $\mathrm{CD}^{+} \mathrm{CD} 8$ - cells.

Statistical analysis. Statistical analysis was performed with SPSS statistical software (SPSS version 9.0; SPSS Inc., Chicago, IL, USA). One-way analysis of variance with multiple comparisons tests (Kruskal-Wallis tests) were used and $\mathrm{P}<0.05$ was considered to indicate a statistically significant difference.

\section{Results}

Peripheral blood cell subgroup changes at progression. Along with chest radiological progression within the first 3 days, in most patients, the NK cell counts were similar to monocyte counts, which both demonstrated a gradual increase, whereas the frequency of $\mathrm{B}$ cells showed an obvious reduction. The frequency of peripheral blood $\mathrm{CD} 4^{+} \mathrm{T}$ cells gradually decreased in all patients, whereas $\mathrm{CD}^{+} \mathrm{T}$ cell frequencies showed a gradual increase in the majority of patients, thus causing a CD4/CD8 imbalance. Among T cell subtypes, Th1 cells, Th2 cells, CD $8{ }^{+} \mathrm{PD}-1^{+} \mathrm{T}$ cells, CD4 ${ }^{+} \mathrm{PD}-1^{+} \mathrm{T}$ cells, Tregs and Th17 cell frequencies fluctuated by $\sim 10 \%$. Notably, peripheral blood CD ${ }^{+} \mathrm{PD}-1^{+} \mathrm{T}$ cells and Th1 cells both demonstrated a slight increase in frequency in all patients, together with a downward trend of Tregs frequencies in most cases (Fig. 1).

Peripheral blood cell subgroup changes during recovery. During recovery, both NK cell and monocyte frequencies were found to be increased initially and gradually reduce again in most patients, whereas all cases were classified as having a reduction in $\mathrm{B}$ cells. As for $\mathrm{T}$ cell subsets, the frequency of $\mathrm{CD}^{+} \mathrm{T}$ cells gradually decreased, whereas $\mathrm{CD}^{+} \mathrm{T}$ cell frequencies showed an initial reduction and a subsequent increase in all patients, to restore the CD4/CD8 balance. Furthermore, peripheral Th1 cell, Th2 cell, CD4 ${ }^{+} \mathrm{PD}-1^{+} \mathrm{T}$ cell, CD8 ${ }^{+} \mathrm{PD}-1^{+} \mathrm{T}$ cell, Tregs and Th17 cell frequencies fluctuated slightly in a narrow range. Among these $\mathrm{T}$ cell subsets, all recovering patients exhibited an increased trend of Tregs frequencies, and in patients who presented with higher levels of Th1 cells, the levels were subsequently reduced during recovery (Fig. 2).

Differences between the progression and recovery periods. The frequencies of the different cell subsets at different periods were statistically compared (Table I). The preliminary 
Table I. Analysis of differences of lymphocyte subgroups in the peripheral blood of patients with influenza A (H7N9) between the progression and recovery periods.

\begin{tabular}{lrrr}
\hline Cell type & Healthy $(\mathrm{n}=8)$ & Progression $(\mathrm{n}=7)$ & Recovery $(\mathrm{n}=5)$ \\
\hline B cells & $12.59 \pm 1.23$ & $36.78 \pm 2.63$ & $19.05 \pm 1.62^{\mathrm{a}}$ \\
NK cells & $16.40 \pm 2.21$ & $18.97 \pm 2.92$ & $18.26 \pm 2.22$ \\
Monocytes & $2.57 \pm 0.47$ & $6.99 \pm 1.31$ & $25.21 \pm 3.31^{\mathrm{a}}$ \\
CD4 ${ }^{+}$T cells & $38.75 \pm 2.40$ & $23.46 \pm 2.43$ & $39.43 \pm 2.33^{\mathrm{b}}$ \\
CD8 ${ }^{+}$T cells & $22.79 \pm 2.16$ & $9.04 \pm 1.54$ & $18.08 \pm 1.50^{\mathrm{a}}$ \\
Th1 cells & $4.16 \pm 0.52$ & $4.17 \pm 0.79$ & $4.33 \pm 0.72$ \\
Th2 cells & $0.35 \pm 0.08$ & $3.60 \pm 0.70$ & $1.69 \pm 0.22^{\mathrm{a}}$ \\
PD- $1^{+} \mathrm{CD} 4^{+}$T cells & $3.78 \pm 0.92$ & $5.90 \pm 0.45$ & $7.52 \pm 0.41^{\mathrm{a}}$ \\
PD- $1^{+}$CD8 ${ }^{+}$T cells & $0.50 \pm 0.15$ & $4.17 \pm 0.79$ & $9.33 \pm 0.81^{\mathrm{a}}$ \\
Tregs & $5.95 \pm 0.56$ & $4.28 \pm 0.43$ & $4.02 \pm 0.31^{\mathrm{c}}$ \\
Th17 cells & $0.29 \pm 0.75$ & $3.40 \pm 0.47$ & $1.71 \pm 0.22^{\mathrm{a}}$ \\
\hline
\end{tabular}

Data are presented as mean \pm standard deviation. ${ }^{\mathrm{a}} \mathrm{P}<0.05 \mathrm{vs}$. the progression and healthy groups, ${ }^{\mathrm{b}} \mathrm{P}<0.05 \mathrm{vs}$. the progression group and ${ }^{\mathrm{c}} \mathrm{P}<0.05$ vs. the healthy group. NK, natural killer; Th, T helper; PD-1, programmed death 1; Treg, regulatory T cell.
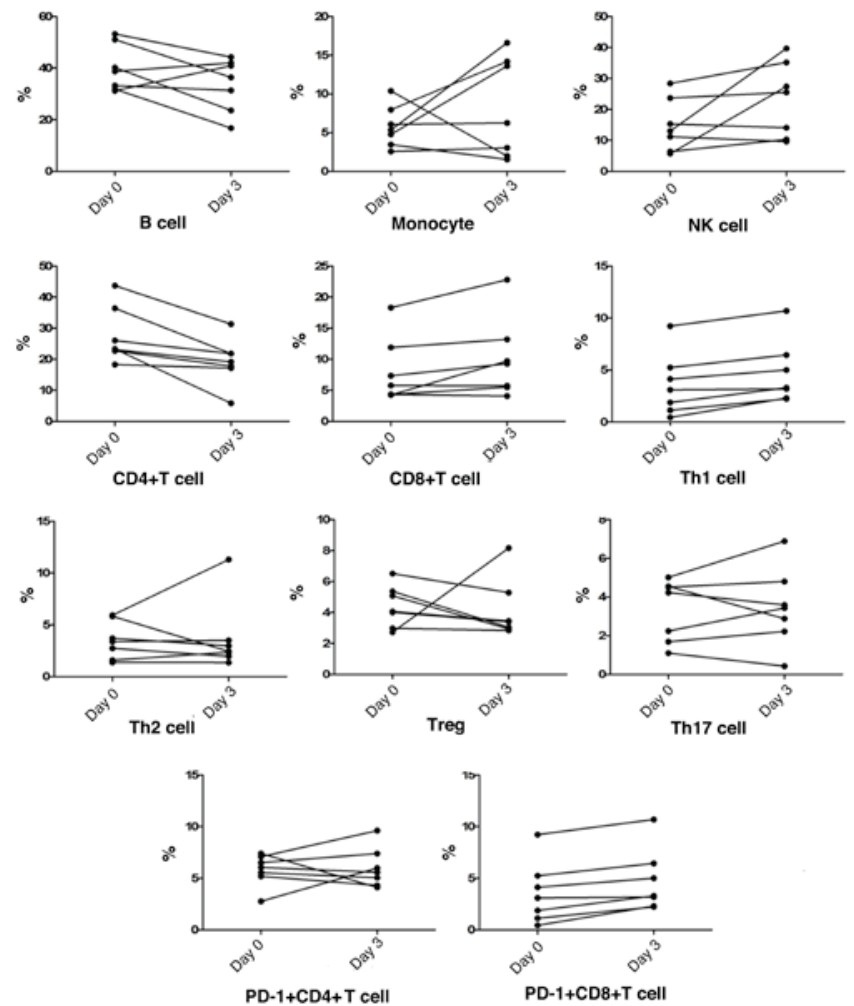

Figure 1. Analysis of dynamic changes in lymphocyte subgroups in the peripheral blood of patients with influenza A (H7N9) in the progression period. Results are presented as a percentage of total peripheral blood leukocytes. NK, natural killer; Th, T helper; PD-1, programmed death 1; Treg, regulatory $\mathrm{T}$ cell.

data from this study showed that the frequencies of B cells, Th2 cells and Th17 cells in the progression period were significantly higher than those in the recovery period $(\mathrm{P}<0.01$, $\mathrm{P}=0.001$ and $\mathrm{P}=0.001$, respectively). The frequencies of $\mathrm{CD} 4^{+} \mathrm{T}$ cells, $\mathrm{CD} 8^{+} \mathrm{T}$ cells, monocytes, $\mathrm{CD} 4^{+} \mathrm{PD}-1^{+} \mathrm{T}$ cells and $\mathrm{CD} 8{ }^{+} \mathrm{PD}-1^{+} \mathrm{T}$ cells in the progression period were less than those in the recovery period $(\mathrm{P}<0.001, \mathrm{P}=0.0003, \mathrm{P}=0.0001$,
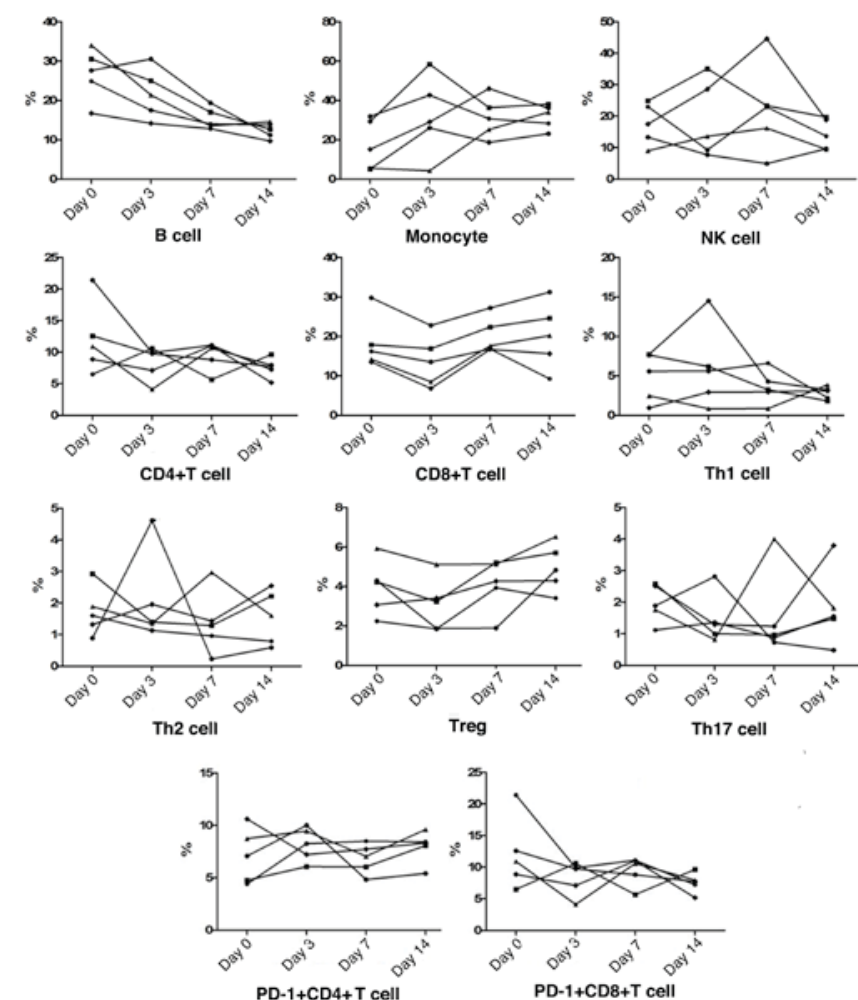

Figure 2. Analysis of dynamic changes in the lymphocyte subgroups in the peripheral blood of patients with influenza A (H7N9) in the recovery period. NK, natural killer; Th, T helper; PD-1, programmed death 1; Treg, regulatory T cell.

$\mathrm{P}=0.013$ and $\mathrm{P}=0.0001$, respectively). The frequencies of $\mathrm{NK}$ cells, Th1 cells and Tregs exhibited no significant differences between the two periods $(\mathrm{P}=0.85, \mathrm{P}=0.88$ and $\mathrm{P}=0.62$, respectively).

When compared with healthy volunteers, it was observed that increases of B cell, Th2 cell and Th17 cell frequencies in the pathogenesis of the critical H7N9 infection occurred and these 
frequencies exhibited a normalization trend during recovery, while reductions of $\mathrm{CD}^{+}{ }^{+} \mathrm{T}$ cell andCD ${ }^{+} \mathrm{T}$ cell frequencies occurred during progression and the frequencies subsequently normalized during recovery. With regard toCD $8^{+} \mathrm{PD}-1^{+} \mathrm{T}$ cell, $\mathrm{PD}-1^{+} \mathrm{CD} 4^{+} \mathrm{T}$ cell and monocyte frequencies, they exhibited further increases during recovery compared with those during progression.

\section{Discussion}

NK cells are the major effector cells during acute infection, rapidly killing infected cells in the process. Previous studies have shown that a reduction in NK cell count occurs mainly because the virus directly infects and kills NK cells, thereby limiting their activity and leading to their apoptosis $(5,6)$. In a study of H1N1-infected patients, the frequency of NK cells in patients with severe and moderate disease was found to be less than that of the control group (6). In the present study, for the majority of patients, although no significant difference in the frequency of NK cells was found between the progression period and recovery, the NK cell frequency demonstrated a gradual increase in the progression period and an early increase and sequential reduction during recovery. Notably, the patients with a higher level of NK cells in the progression period exhibited a quicker recovery from the disease. In conclusion, when infection is accompanied by a dynamic NK cell change, this could indicate that the body is in a balance between anti-infective immunity and autoimmune damage.

Previously, mononuclear cell infiltration and alveolar cell desquamation have been described during the acute phase of severe acute respiratory syndrome, together with dysregulation of plasma cytokine levels (7). Exposure of monocytes or macrophages to viruses causes the release of proinflammatory cytokines, such as TNF- $\alpha$, IL-1 and IL-6, and chemokines, as well as members of the CC-chemokine subfamily such as MIP-1 $\alpha$, MCP-1 and RANTES, which preferentially attract monocytes and lymphocytes (8). In the present study, for most patients, the frequency of monocytes in the progression period was less than that during recovery, and the monocyte counts demonstrated a gradual increase in the progression period and an early increase and subsequent reduction during recovery. It is hypothesized that the increase of monocyte frequency in the progression period exhibits both immune protective and chemoattracting functions, and its subsequent reduction was important in achieving balanced cytokine production.

$\mathrm{CD}^{+}$and $\mathrm{CD} 8^{+} \mathrm{T}$ cells are associated with viral immunity and a lack of these cells would lead to a delay in viral clearance and an increase in mortality. In an animal study, it was found that $\mathrm{CD}^{+} \mathrm{T}$ cells, $\mathrm{CD} 8^{+} \mathrm{T}$ cells and $\mathrm{B}$ cells achieved peak values within 5-6 days after swine-origin influenza A virus infection (9). In accordance with previous data concerning $\mathrm{H} 1 \mathrm{~N} 1$, which indicated that the frequency of B cells in patients with severe disease was significantly higher than that in patients with moderate disease and the control (10), the present study showed that $\mathrm{CD}^{+}{ }^{+} \mathrm{T}$ cells, $\mathrm{CD} 8^{+} \mathrm{T}$ cells and $\mathrm{B}$ cells all demonstrated detectable changes, which included an imbalance of CD4/CD8 in the progression stage, together with a continuous reduction in $\mathrm{CD} 4^{+} \mathrm{T}$ cells and $\mathrm{B}$ cells. This could indicate that the disease progression may be attributed to inhibition of the antiviral immune response of $\mathrm{T}$ cells, thereby causing the CD4/CD8 ratio to balance during recovery, and a downregulation of B cell-induced humoral immune responses against H7N9 virus.

No statistically significant changes were found during the continuous monitoring of $\mathrm{CD} 4^{+} \mathrm{IFN}-\gamma^{+} \mathrm{T}$ cell, $\mathrm{CD} 4^{+} \mathrm{IL}-4^{+}$ $\mathrm{T}$ cell, $\mathrm{CD} 4^{+} \mathrm{PD}-1^{+} \mathrm{T}$ cell, $\mathrm{CD} 8^{+} \mathrm{PD}-1^{+} \mathrm{T}$ cell, Tregs and Th17 cell frequencies of patients with severe H7N9 in the progression period, or during recovery. However, despite the relatively low numbers of study subjects, the observations of the present study indicate that there are persistent abnormalities of these $\mathrm{T}$ cell subsets in patients who have suffered from H7N9 infection. In the progression period, although $\mathrm{CD} 4^{+} \mathrm{IFN}-\gamma^{+} \mathrm{T}$ cell frequencies increased, $\mathrm{CD} 8^{+} \mathrm{PD}-1^{+} \mathrm{T}$ cell frequencies also increased in all patients, together with higher levels ofCD $4^{+} \mathrm{IL}-4^{+} \mathrm{T}$ cells, which might induce the inhibition of Th1 cell-mediated antiviral immunity. In support, during recovery, the Th1/Th2 balance was maintained, and $\mathrm{CD} 8^{+} \mathrm{PD}-1^{+} \mathrm{T}$ cell frequencies demonstrated a mild downward trend in the majority of cases. With regard to regulatory $\mathrm{T}$ cells, a downward trend of Treg frequencies in the majority of cases might contribute to an enhancement of the immune response to virus during disease progression, along with subsequent uncontrolled immune damage in patients with H7N9 infection (11). It was also found that the frequency of Th17 cells in the progression period was significantly higher than that in recovery, which suggested that Th17 cells promote pathogenesis of the disease. In addition, pro-inflammatory cytokine responses, characterized by a combined Th1/Th17 cytokine induction may be responsible for the disease progression of patients with H7N9 infection (12).

In present study, it was noted that the immune cell changes in H1N1- and H7N9-infected patients differ. This could be associated with $\mathrm{T}$ cells, the peak detection of which may have been missed because of failure to diagnose and treat the disease at an early stage. Furthermore, a study by Cao et al has indicated that the incidence of severe H1N1 is highest in the 15- to 19-year-old age group and lowest for patients aged $>65$ years (13). However, the clinical data in the current study indicated that the most severe H7N9 infections occurred in individuals $>60$ years old. This difference in patient age might be responsible for differences in immune cell differences between H1N1- and H7N9-infections.

In conclusion, H7N9 infection stimulates host and cellular immune responses. Each lymphocyte subgroup in patients infected with the H7N9 virus plays a more important antiviral role in the early stages of infection, but an excessive immune response leads to an increase of immunological injury, and establishment of immunological homeostasis is helpful to control the disease. Since the preliminary results reported in the present study were based on a small sample, further studies with larger sample sizes are required to verify and extend its findings.

\section{Acknowledgements}

This study was supported by Clinical Medical Center of Suzhou (no. SZZX201502), Suzhou Key Laboratory for Respiratory Medicine (no. SZS201617), Projects of the Department of Health of Jiangsu Province (no. QNRC2016748) and the Natural Science Foundation of Jiangsu Province University (no. 13KJB320021). 
The authors would like to acknowledge Professor Xue-Guang Zhang of The First Affiliated Hospital of Soochow University for providing constructive criticism and helpful suggestions for this manuscript.

\section{References}

1. Wang XF, Shi GC, Wan HY, Hang SG, Chen H, Chen W, Qu HP, Han BH and Zhou M: Clinical features of three avian influenza H7N9 virus-infected patients in Shanghai. Clin Respir J 8: 410-416, 2014.

2. Gao HN, Lu HZ, Cao B, Du B, Shang H, Gan JH, Lu SH, Yang YD, Fang Q, Shen YZ, et al: Clinical findings in 111 cases of influenza A (H7N9) virus infection. N Engl J Med 368: 2277-2285, 2013.

3. Koyama S, Ishii KJ, Coban C and Akira S: Innate immune response to viral infection. Cytokine 43: 336-341, 2008.

4. Heltzer ML, Coffin SE, Maurer K, Bagashev A, Zhang Z, Orange JS and Sullivan KE: Immune dysregulation in severe influenza. J Leukoc Biol 85: 1036-1043, 2009.

5. Mao H, Tu W, Qin G, Law HK, Sia SF, Chan PL, Liu Y, Lam KT, Zheng J, Peiris M and Lau YL: Influenza virus directly infects human natural killer cells and induces cell apoptosis. Virol 83: 9215-9222, 2009

6. Giamarellos-Bourboulis EJ, Raftogiannis M, Antonopoulou A, Baziaka F, Koutoukas P, Savva A, Kanni T, Georgitsi M, Pistiki A, Tsaganos T, et al: Effect of the novel influenza A (H1N1) virus in the human immune system. PLoS One 4: e8393, 2009.
7. Tse GM, To KF, Chan PK, Lo AW, Ng KC, Wu A, Lee N, Wong HC, Mak SM, et al: Pulmonary pathological features in coronavirus associated severe acute respiratory syndrome (SARS). J Clin Pathol 57: 260-265, 2004.

8. Wang CH, Liu CY, Wan YL, Chou CL, Huang KH, Lin HC, Lin SM, Lin TY, Chung KF and Kuo HP: Persistence of lung inflammation and lung cytokines with high-resolution CT abnormalities during recovery from SARS. Respir Res 6: 42, 2005.

9. Lange E, Kalthoff D, Blohm U, Teifke JP, Breithaupt A, Maresch C, Starick E, Fereidouni S, Hoffmann B, Mettenleiter TC, et al: Pathogenesis and transmission of the novel swine-origin influenza virus $\mathrm{A} / \mathrm{H} 1 \mathrm{~N} 1$ after experimental infection of pigs. J Gen Virol 90: 2119-2123, 2009.

10. Guo X, Chen Y, Li X, Kong H, Yang S, Ye B, Cui D, Wu W and Li L: Dynamic variations in the peripheral blood lymphocyte subgroups of patients with 2009 pandemic H1N1 swine-origin influenza A virus infection. Virol J 8: 215, 2011.

11. Joedicke JJ, Dietze KK, Zelinskyy G and Dittmer U: The phenotype and activation status of regulatory $\mathrm{T}$ cells during Friend retrovirus infection. Virol Sin 29: 48-60, 2014.

12. Tan HL and Rosenthal M: IL-17 in lung disease: Friend or foe? Thorax 68: 788-790, 2013.

13. Cao B, Li XW, Mao Y, Wang J, Lu HZ, Chen YS, Liang ZA, Liang L, Zhang SJ, Zhang B, et al: Clinical features of the initial cases of 2009 pandemic influenza A (H1N1) virus infection in China. N Engl J Med 361: 2507-2517, 2009. 